\title{
Periferias urbanas: retrato del extrarradio barcelonés en las novelas de Javier Pérez Andújar
}

\author{
David García PONCE \\ Departamento de Filología Hispánica \\ Universidad de Barcelona \\ davidgponce@gmail.com
}

Recibido: $16 / 03 / 2015$

Modificado: $13 / 09 / 2015$

Aceptado: 08/02/2016

\section{Resumen}

Javier Pérez Andújar, a través de su propia memoria, crea en Los príncipes valientes (2007) y Paseos con mi madre (2011) un retrato detallado del extrarradio barcelonés. En ambas novelas, el autor combina diferentes elementos: la memoria oral, la metaliteratura, la crónica y la cultura popular. De este modo narra la historia de tres generaciones ubicadas en las afueras de la ciudad. El presente artículo centra su análisis, basándose en una contextualización histórica, en la configuración del espacio y el estudio de las características morfológicas y sociales propias de los extrarradios. Con ello se pretende demostrar la significación histórica y social del extrarradio en la historia contemporánea de Barcelona.

Palabras clave: autoficción, democracia, extrarradio, metaliteratura, periferia.

Title: Urban peripheries: portrait of outskirts in Javier Pérez Andújar's novels

\section{Abstract}

Javier Pérez Andújar, writing his own memory, creates in Los príncipes valientes (2007) and Paseos con mi madre (2011) a deep portrait of the outskirts of Barcelona. In both novels, the author combines different elements: the oral memory, metafiction, reports and popular culture. With all these elements, Pérez Andújar explains the story of three generations who live in the surroundings of the city. The article focuses its analysis, based on a historical context, on the configuration of the space and the analysis, reflected in both novels, of the morphological and social characteristics typical of the outskirts. This way, the historical and social significance of the suburbs of Barcelona is demonstrated.

Key words: autofiction, democracy, outskirts, metafiction, periphery.

\section{Índice}

1. Introducción

2. De la autoficción a la autorreferencialidad

3. La configuración del espacio

4. Moradores del extrarradio

5. La historia social: entre octavillas, huelgas y encerronas

6. Conclusiones 


\section{Introducción}

Con la publicación de Los príncipes valientes (2007) y Paseos con mi madre (2011), Javier Pérez Andújar (San Adrián del Besós, 1965) crea un friso argumentativo en el cual narra, a través de la memoria y de sus vivencias propias, la vida en una población del extrarradio ${ }^{1}$ barcelonés $y$, a su vez, expone los rasgos característicos de los espacios ubicados en las afueras de una gran ciudad.

La representación literaria de la periferia se hace un hueco en la novela a finales del siglo XIX con el Realismo y el Naturalismo. En este periodo, los autores proyectan un ensanchamiento temático de la ciudad. Este interés por la realidad que se vive en las afueras de la urbe tiene una notable presencia en la novela del medio siglo. Sin embargo, en las últimas décadas este locus urbano no ha generado mucha materia literaria. En cierto modo, Pérez Andújar suple un olvido literario en la novela contemporánea ${ }^{2}$, la cual ha explorado poco los espacios que delimitan las grandes ciudades así como el paisaje urbano que se divisa en las últimas paradas del transporte público.

${ }^{1}$ Este espacio se puede denominar periférico, extrarradio e incluso suburbio. Los dos primeros términos ubican una parte de la ciudad que queda al margen. Sin embargo, el término periferia tiene otras acepciones no exclusivamente geográficas. Por tanto, se empleará el término extrarradio, entendiéndolo como "espacio que rodea una población", ya que tiene un significado concreto en la geografía urbana y se asocia a una realidad social que, en términos generales, encarna algunos de los temas de las obras que se analizan en este artículo. No obstante, Carles Ferrer, en su artículo "Perifèries literàries" (Ferrer 2014: 12), considera que el término periferia es adecuado, ya que tiene un antónimo centro que sería el espacio opuesto y que permite desarrollar una crítica social y espacial. Por ello, el título del artículo parte de una ubicación general -la periferia- y en el subtítulo se concreta un sector determinado de esta zona urbana. Utilizaremos ambos términos en el desarrollo del artículo.

${ }^{2}$ Carles Carreras, en su estudio La Barcelona literaria (2003), pone en evidencia la escasa presencia de la periferia barcelonesa. Carreras sostiene la idea de que la realidad cotidiana de los alrededores de la ciudad y los acontecimientos históricos vividos no han tenido un interés literario salvo para los habitantes de la propia periferia (Carreras 2003: 175-180). Opinión paralela expresan Jaume Fuster y Manuel Vázquez Montalbán en Diàlegs a Barcelona (1985). El primero opina que se ignora bastante el área metropolitana en su conjunto (1985: 19) y Vázquez Montalbán considera que no se ha aprovechado el filón estético-temático y que no se ha analizado en profundidad la subcultura urbana creada en estos espacios (1985: 24). Stewart King, en Escribir la catalanidad (2005), analiza cómo la presencia literaria tanto de los emigrantes en Cataluña como de los espacios donde estos habitan es más frecuente en autores que tienen un vínculo con esa sociedad (King 2005: 90). Para el autor, estos espacios se definen en oposición a los espacios de los nativos, ya que proliferaron en momentos de represión cultural. En definitiva, estos espacios plantean un conflicto cultural e incluso lingüístico (King 2005: 90). 
El autor ubica sus obras al otro lado del río Besós, en el norte de la ciudad. Pérez Andújar encuentra en el espacio una sustancia crítica que le permite narrar una memoria colectiva y personal:

Sentiré que es necesario escribir, que es preciso dejar constancia de ella [la historia], en un afán notarial de levantar acta de la vida, acaso ya intuyendo que la democracia de la historia reside en que no sólo la escriban los vencedores. (Pérez Andújar 2007: 26)

\section{De la autoficción a la autorreferencialidad}

El fragmento anterior es una declaración de intenciones que el autor hace en Los príncipes valientes y más tarde mantendrá en Paseos con mi madre. Ambas novelas parten de unas vivencias personales y otras colectivas que el protagonista conoce a través de la transmisión oral. Los príncipes valientes narra la infancia y juventud del autor y los recuerdos que le llegan de sus antepasados, procedentes del Sur de España y que se instalaron en el extrarradio de la ciudad. La primera generación abandona su origen rural para instalarse en el suburbio de una gran capital; la segunda, a la que pertenecen los padres del protagonista, vive los años de reivindicaciones vecinales en los albores de la democracia, y la tercera, la del protagonista, vive los cambios del presente mientras escucha historias contadas por la familia, así como otras historias que aprende a través de las novelas. Las vivencias del presente se solapan con los recuerdos creando dos espacios temporales simultáneos. De hecho, las tres generaciones aparecen en un mismo plano.

El protagonista carece de nombre propio y se limita a recordar y ser espectador de cuanto encuentra y recuerda en sus paseos: "de toda la vida, preferiré ser amigo o compañero del protagonista antes que protagonista" (Pérez Andújar 2007: 18). Empleando el futuro histórico, narra el pasado subrayando la persistencia de su figura y de sus valores en el tiempo.

En Paseos con mi madre recuerda a las generaciones anteriores: "Llevaba más de una década llegando gente a la ciudad en continuas oleadas, emigrantes que venían, que veníamos, de todas partes de España (pero la verdad es que yo nací aquí, y de esa incertidumbre trata este libro)" (Pérez Andújar 2011: 137). No obstante, en esta obra, el auto-protagonista se adelanta en el tiempo, situándose unos años después, cuando se da por supuesto que ya no vive en su población natal pero regresa para visitar a su madre y, con ella, "siguiendo la orilla del río [...] En nuestro paseo, nos ponemos a recordar" (Pérez Andújar 2011: 11-12), consciente de que "aquí ya no hay nada de lo que persigo. Son fantasmas lo que salgo a cazar, y a algunos voy a encontrármelos" (Pérez Andújar 2011: 14). 
El autor instaura un pacto con el lector en cuanto que nos sitúa en un lugar concreto y nos hace saber la intención que tiene. No pretende ser el protagonista ni en una ni en otra obra, pero sí expresa su voluntad de explicar: "Voy a decidirme a escribirme a mí mismo, y puestos a retratar, en todo caso, elegiré hacerme, antes que fotógrafo de sucesos, fotógrafo de palabras" (Pérez Andújar 2007: 26). Para ello, emplea diferentes técnicas narrativas que van desde el testimonio personal hasta la crónica. Pérez Andújar emplea algunos materiales ficcionales como son los paseos, e incluso algún personaje inventado como Ruiz de Hita, un guiño al autor del Libro del buen amor. No obstante, la mayor parte de los materiales que emplea son verídicos y están ordenados de forma que no obedecen a un orden cronológico sino a un dispositio arbitraria, fruto del punto de vista personal del autor. Ambas obras rompen con el pacto autobiográfico, ya que el lector no lee una autobiografía en la cual al autor se le exija la verdad y que Lejeune definiría como: "Récit retrospectif en prose qu'une personne réelle fait de sa propre existence, lorsqu'elle met l'accent sur sa vie individuelle, en particulier sur l'histoire de sa personnalité" (Catelli 2007: 278).

En ambas novelas el lector encuentra una verosimilitud literaria que hace creíble lo que cuenta la obra. Para ello, el autor crea una arquitectura textual con vetas barrocas marcada por un cuidado preciso del lenguaje. La voz narrativa habla del pasado mientras se proyecta hacia el futuro; es la voz de un niño y más tarde la de un joven que reflexiona sobre todo cuanto recuerda y vive. El narrador se ubica en una doble perspectiva, dos planos, el de su vivencia y el de sus recuerdos. En este punto, el autor se encuentra cercano al espacio que recorre y distante a la vez.

Este narrador-personaje-autor de ambas obras trabaja con una libre disposición de materiales, con "un hibridismo que admite todas las gradaciones" (Casas 2012: 11), hecho que nos lleva a adscribir ambas novelas al género de la autoficción.

La diégesis adquiere una interpretación propia por parte del autor que de modo arbitrario narra en las dos novelas. La mayoría de los episodios tienen un "valor documental en una construcción histórica, en un relato con atribuciones de verdad" (Pozuelo Yvancos 1993: 190). Sin embargo, el autor-narrador-protagonista se escinde, y el yo protagonista crea una ficcionalización de los hechos que lo separa del pacto lejeuniano. Pérez Andújar en sus paseos llega a lo que Nora Catelli ha llamado "hendiduras y cráteres de lo escondido". Según Catelli, con este procedimiento, un autor proclama que "él fue aquello que hoy escribe" (apud Pozuelo Yvancos 1993: 194). En efecto, el autor deja constancia de la importancia que tiene el espacio biográfico. Además, el autor crea un juego metaliterario ya que hace referencia al proceso de gestación de la obra, menciona los escritores y las series de televisión que le inspiran y, aun más importante, los 
motivos que le impulsan a ello. Esto nos lleva a corroborar la presencia en ambas obras de la autorreferencialidad, que Sobejano ha definido como "reflexión autocrítica sobre el proceso de escribir" (1985: 26). En efecto, el autor admite: "no puedo pertenecer más que a mi propia biografía" (Pérez Andújar 2007: 146), una historia en la cual muestra cierta ambivalencia de pertenencia al espacio y una necesidad de conocer y escribir sobre el pasado de los suyos; para ello afirma: "voy a decidirme a escribirme a mí mismo" (Pérez Andújar 2007: 26) a la vez que revela el proceso de creación literaria.

\section{La configuración del espacio}

El río Besós es el eje en torno al cual se articulan los paseos del protagonista. El río representa un espacio referencial en cuanto que nos ubica en unas coordenadas geográficas $y$, por otro lado, un espacio simbólico, ya que se trata de la línea divisoria entre dos espacios, la ciudad y la periferia. En este enclave se encuentra el autor algunas veces con su tío y otras con su amigo Ruiz de Hita en Los príncipes valientes, y con su madre en la siguiente novela. Con ellos paseará a través del recuerdo de experiencias vividas en su infancia y juventud, y de historias contadas por sus padres y abuelos. Tanto las historias del presente como la mayoría de las del pasado tienen en común que transcurren en el extrarradio.

Como si de un flâneur se tratase, el autor pasea "hilvanando ideas" (Pérez Andújar 2011: 48), escribe al andar y deambula por los espacios presentes $y$, mediante el recuerdo, por los de su infancia y juventud. En ninguna de las dos novelas se traza un itinerario. La actitud del autor se asemejaría al concepto de flâneur de Walter Benjamin: "una especie de topógrafo urbano capaz de descifrar en todos sus aspectos a la ciudad ya que en esta, como en su casa, está inmerso en su accesibilidad, movilidad y equipamiento urbano" (Benjamin 1998: 51).

El autor delimita los espacios que rodean la ciudad y define el territorio llamado área metropolitana: "donde en más de seiscientos kilómetros cuadrados viven tres millones de personas repartidas aglutinadas en comarcas: el Barcelonés, el Vallès Occidental y el Baix Llobregat" (Pérez Andújar 2011: 33), que define como "el cinturón rojo" 3 y aborda la cuestión de la bipolaridad entre centro y periferia: "La ciudad no vive de espaldas al mar, vive de espaldas a su gente y a sus vecinos porque no siente nada por ellos. Cuando Barcelona visita a sus vecinos es para plantarles una incineradora de basuras" (Pérez Andújar 2011: 43).

3 Este apelativo debe su nombre a la vinculación política de la mayoría del extrarradio de Barcelona con los partidos de izquierda que, desde el inicio de la Democracia hasta las últimas elecciones, han compuesto la mayor parte de los equipos municipales. 
Esta bipolaridad crea una frontera que para Enric Bou juega un doble papel en la literatura ya que abre las puertas a la imaginación, mientras que es un medio para limitar el texto o, por el contrario, la supresión de los límites de la imaginación (Bou 2013: 100). Pérez Andújar delimita los espacios con unas líneas divisorias que son carreteras, puentes, vías del tren, descampados, algo frecuente en el imaginario del extrarradio ${ }^{4}$. A la vez que desarrolla la idea de frontera imaginaria para separar dos espacios diferenciados: "Nuestra Barcelona no llegaría nunca hasta Barcelona. Y, al revés, para llegar a nuestra Barcelona habrá que ir más allá de donde alcanza el metro" (Pérez Andújar 2011: 23).

El núcleo de relación entre los habitantes es el barrio, que "se erige como el espacio de vida y evolución social que, según Bastien, la comunidad acaba reconociendo como propio" (Calvo 2010: 68). Es el lugar que cada habitante conoce y frecuenta más que cualquier otro lugar, ya que muchos moradores no trascienden la frontera del propio barrio. Según Xavier Domènech es el entorno donde se expresan "sentimientos de identidad y solidaridad vitales que contribuyeron a la emergencia de una cultura comunitaria" (apud Tébar Hurtado 2011: 96).

En ambas obras, el autor aporta unas descripciones del espacio sin configurar un plano detallado. Insiste más en el efecto que produce en su mirada:

Es una calle larga, eso sí, y la atraviesan en su viaje algunos callejones edificados con casas de hormigón de una planta y puerta de madera. Parece a ratos casas de pueblo y a ratos la rebaba del barroquismo. Esta mezcla entre campo y extrarradio sirve asimismo para describir la fisonomía de la gente de los barrios, de las ciudades que rodean Barcelona. (Pérez Andújar 2011: 70)

Estos espacios están definidos como lugares marcados por la estética de la fealdad, a menudo carentes de equipamientos y de mala calidad de construcción:

Los bloques nuevos empiezan a reemplazar a los primeros que hubo, porque se estaban desmoronando por la aluminosis y otras taras de la construcción que separan el hormigón de las vigas como carne que se desprende de los huesos. Estos edificios fueron levantados en los

${ }^{4}$ Esta imagen impersonal que aparece en muchas producciones cinematográficas de los años setenta y ochenta ha llevado a algunos críticos, generalmente de cine, a definir estos espacios con el término acuñado por Marc Augé de no-nugar para referirse a aquellos lugares donde no se crea "ni identidad ni relación" (Augé 1998: 107). En mi opinión, es discutible aplicarlo a estos espacios (puentes, descampados, etc.) en el contexto de la periferia urbana, ya que acostumbran a ser lugares de encuentro y de socialización de sus habitantes, por lo general, población joven. 
años sesenta y setenta, y todavía quedan en pie muchos de ellos, algunos con las paredes derrumbadas del todo, otros con la portería cegada con ladrillos, y con una visera de uralita para contener los escombros que van cayendo [...]. Todos estos bloques son ruinas vivientes que no simbolizan el fin de una época sino el fin de unas vidas, las de la gente que llegó a Barcelona, se metió en barracas y luego fue a parar a este lugar, a estos almacenes de carne de cañón de cincuenta y cinco metros cuadrados con ventana enrejada, y aquí tuvo que quedarse para siempre apartada de todas las oportunidades. (Pérez Andújar 2011: 128-129)

En Los príncipes valientes se explican los inicios de los barrios periféricos, sin embargo, en Paseos con mi madre se narra la evolución urbanística que supuso el paso de las barracas a las construcciones verticales: "También voy a pretender ser o haber sido un hombre de campo como mi abuelo lo fue, o como lo es mi tío incluso en Barcelona, en las barracas y las casas que hay junto al río" (Pérez Andújar 2007: 55), mientras que años después "Barcelona no es una ciudad de rascacielos. Lo más parecido a los rascacielos los han levantado en los municipios de las afueras donde vivimos, que la arropan como una visión de cemento" (Pérez Andújar 2007: 75-76).

Una de las características del extrarradio de las ciudades es la condición mutante, lo que el autor llama los trasbarrios para referirse al desplazamiento de los barrios marginales hacia otras zonas salientes de la ciudad: "Todos los barrios tienen un trasbarrio al que ni ellos miran, un barrio que sigue como una pregunta sigue a otra pregunta" (Pérez Andújar 2011: 150). El autor traza un paralelismo en la forma de vida, e incluso en el paisaje urbano de un lado y del otro de la ciudad. Por eso, se puede considerar que la población de San Adrián del Besós es un epítome de lo que sería un espacio periférico:

Comprendí cómo funcionaba la simetría de la ciudad. Vi que lo que había ocurrido en el otro lado de Barcelona era lo que pasaba exactamente en el nuestro, con las mismas chicas, los mismos bloques y nosotros mismos. Vi que acaso Barcelona no existía para nosotros, que era un espejo en el que uno podía reflejarse, el marco de un espejo vacío por el que nuestro doble nos hacía un gesto de desprecio. (Pérez Andújar 2011: 156) 


\section{Moradores del extrarradio}

Dos son los protagonistas del extrarradio: el emigrante y la clase obrera. En Príncipes valientes, se narra la llegada de emigrantes procedentes de las áreas menos desarrolladas de la península. Estos recién llegados se instalaron en zonas suburbiales pobladas por viviendas autoconstruidas en pésimas condiciones que serían las barracas. Su familia es un ejemplo de ello. A través del testimonio oral de sus familiares, el autor narra las penurias a las que se vieron sometidos. Una segunda generación, como indica el autor, que ya está en edad de jubilación y la suya.

En Paseos con mi madre, el autor se centra en la segunda generación de inmigrantes, aquellos que instalados en el extrarradio transitan de los actos clandestinos al proyecto de construcción democrática:

Va mi padre en otro piquete con sus compañeros del sindicato, y yo me veo, antes que unido a una clase, unido a mi viejo. Hogueras en medio de las calles para calentarse en la madrugada, para ver el mundo con la luz roja de una aurora roja que yo voy iluminando de literatura barojiana. (Pérez Andújar 2011: 165)

Uno de los rasgos que suele identificar al habitante del extrarradio es su compleja vinculación con el espacio:

Bloques achaparrados dejados a saco en el descampado como si a las constructoras les hubiera sobrado una partida de cemento después de sus desmanes, y donde los vecinos han tenido que convertir el barro en césped y los bajos de sus edificios en asociaciones culturales. (Pérez Andújar 2011: 153)

La cita anterior hace referencia a las asociaciones que velaban por mantener los lazos culturales con las tierras de origen de los habitantes, pero que también creaban un sentimiento de unión entre la comunidad. No obstante, se trata de habitantes que no tienen una vinculación afectiva con el espacio ya que sus raíces están en otros lugares. Sin embargo, defienden y pugnan por conseguir un reconocimiento en la sociedad. Un tema latente en Paseos con mi madre es el sentimiento de pertenencia a la periferia y la sensación de exclusión del centro de la ciudad. El propio autor considera que "antes que a ningún otro país voy a pertenecer a esta paisajística" (Pérez Andújar 2011: 108); sin embargo, no hay una sensación de pertenencia total ya que en otro momento de sus reflexiones dice: "pero la verdad es que yo nací aquí, y de esa incertidumbre trata este libro" (Pérez Andújar 2011: 137). Con estas palabras se aprecia un desapego hacia el centro de la ciudad que es vivida con una distancia afectiva: 
De nuestra casa en San Adrián, estaban más cerca los bloques del suburbio de La Chana, en Granada [...], que de Pedralbes, Sant Gervasi o la Bosanova, que es donde contaban que vivían los ricos. La Sagrada Familia no formaba parte de nuestra familia. (Pérez Andújar 2011: 20)

Esto lleva al autor a criticar, sin recurrir a una clave nostálgica, la pérdida de conciencia de este espacio por parte de las nuevas generaciones: "siendo de barrio no querré yo ser de barrio, donde tan difícil es leer, sino del espacio exterior, pertenecer a otra nada más lejana y más oscura y también más infinita" (Pérez Andújar 2011: 79), afirmación que contradice en otros momentos, en los cuales pone de manifiesto que pertenece al lugar donde le ha correspondido vivir: "Antes que sentirme de ningún país, de ninguna patria o nación, voy a pertenecer a la internacional de los bloques" (Pérez Andújar 2011: 107).

Parte de esta reivindicación la proyecta en la defensa de la cultura popular. Esta cultura popular ${ }^{5}$ no tiene una acepción elitista, se trata de series de televisión, cómics, personajes de ficción, películas, etc., que hacen la función de recursos intertextuales en ambas obras. El autor, que ya pertenece a una generación que se ha formado entre lo culto y la cultura de masas, cita los cómics y los personajes de su imaginario infantil, las novelas de quiosco:

[...] también percibiré que me ha tocado vivir escindiéndome entre esa tradición popular y una nueva cultura popular a la que del mismo modo pertenezco, o quiero pertenecer, que ha irrumpido en mi vida de una manera ajena e incomprensible para mi familia, a través de la televisión y de los tebeos y del cine y de las revistas de cine y de los anuncios de revistas... (Pérez Andújar 2007: 149)

No solo le interesan los personajes en sí, sino la interpretación que se les dio en la vida del extrarradio y que, como decía Jaume Fuster, "estos espacios generan una subcultura urbana" (Fuster Vázquez Montalbán 1985: 24), construyen unos mitos culturales como símbolo de identidad. En algunos casos, estas expresiones culturales, rock and roll, grafitis canalizan los sentimientos y expresan las rebeldías particulares de una comunidad. Es decir, el autor configura el espacio a través del recuerdo y de la plasmación de

\footnotetext{
${ }^{5}$ Entendiendo por populares, según Michel Hasting, aquellas actividades que por su naturaleza, acciones y relaciones se llevan a cabo dentro del espacio de movimiento de la clase obrera, es decir, un espacio vital delimitado por los barrios o espacios periféricos en un momento histórico preciso (Hasting 1991). En esta línea, Antonio Gramsci considera que la literatura debe aunar lo culto y lo popular con el fin de ser un medio educativo (1967: 233).
} 
un imaginario cultural, en el cual se solapan vivencias con referencias intertextuales.

La mutación del espacio que antes se indicaba también la podemos encontrar en el movimiento migratorio en cuanto que los asentamientos se desplazan de unas zonas a otras y la inmigración es internacional: "Chinos, magrebíes, latinos, subsaharianos... están llenas estas calles de niños de todo el mundo que ya han nacido aquí [...]. Voy a verme en esa chiquillería y lo que encuentro en ella es que venimos del mismo sitio, de las afueras" (Pérez Andújar 2011: 7071); y se conservan algunas costumbres como la de realquilar y la de desplazar a los inmigrantes.

El habitante del extrarradio barcelonés se ha encontrado con un paisaje lingüístico bilingüe. Un bilingüismo que no responde a una paridad de uso. El autor se sirve de unas páginas de Paseos con mi madre para explicar la entrada en el extrarradio de una lengua considerada foránea y cómo, a través de la normalización lingüística ${ }^{6}$, la lengua catalana paulatinamente se incorpora en la periferia.

Se diría que el sentimiento de no pertenencia se extiende al ámbito lingüístico. Una buena parte de los habitantes entendían la lengua, sin embargo, no hacían uso de ella ni la incorporaban a su identidad cultural. Tal realidad llevaría a una situación de diglosia, pues cada lengua es empleada para usos diversos y en registros diferentes. En el caso de Barcelona, el extrarradio ha representado una frontera lingüística, sin quedar este espacio exento de interferencias léxicas, como se aprecia a continuación:

Ignasi hablaba conmigo en castellano; pero con su familia y con la mayoría de los amigos lo hace en catalán. Hablamos como respiramos. Los idiomas se mezclan en la calle igual que en los pulmones el oxígeno se mezcla con la sangre. En los primeros años, en mi barrio, en los bloques, el catalán lo utilizará muy poca gente; donde lo habla todo el mundo es en las zonas más antiguas de San Adrián. Aquí el catalán será sobre todo la lengua de los viejos y de los comerciantes. A nosotros irá llegándonos poco a poco, porque va a ser este idioma el que tenga que dirigirse hacia nosotros, y no nosotros los que vayamos hacia él [...]. Los adultos empezarán a decir chamarreta y rachola, y los niños pegadosa y baldufa. (Pérez Andújar 2011: 105)

${ }^{6}$ Proceso iniciado a partir de la Constitución de 1978, en la cual se reconocen las comunidades autónomas con dos lenguas oficiales. A partir de entonces comienza el proceso de incorporación de la lengua catalana a los diferentes ámbitos de la cultura y la sociedad. 


\section{La historia social: entre octavillas, huelgas y encerronas}

Los espacios periféricos han sido hervideros de tensiones sociales. Por su ubicación, han quedado desplazados de momentos de esplendor de la ciudad y, según muestra el autor, han acogido "lo que ya nadie quiere" (Pérez Andújar 2011: 68). Sin duda, la clase obrera tiene un protagonismo en la historia social del extrarradio. Esta clase se ha visto afectada por las desigualdades sociales, es el sector más sensible a las crisis económicas y el autor se siente unido a esta clase como manifiesta en la entrevista publicada en la revista Quimera: "yo tengo mi centro de interés. Culturalmente, el idealismo obrero, la lucha de clases..." (Pérez Andújar 2014: 16).

Pérez Andújar es filólogo de formación, pero ha desarrollado una actividad periodística, la cual menciona en las novelas, ello le lleva a adoptar la técnica de la crónica cuando narra con precisión algunas historias como la de Manuel Fernández Márquez, una de las tantas reivindicaciones obreras que tuvieron el extrarradio como escenario en el tardofranquismo. Fernández Márquez era un obrero de la compañía FECSA que trabajaba en la construcción de la Central Térmica del Besós y que fue asesinado por la policía en una huelga organizada por los trabajadores en 1973. De nuevo se destaca la hibridación de estilos.

Según Valbonesi, el extrarradio ha crecido en función de las necesidades del centro, que ha desplazado hacia la periferia los equipamientos y espacios que no podía acoger en la ciudad, sin que esto haya respondido a un acto de sociabilización (Valbonesi Prieto 2001: 107). El extrarradio ha sido un lugar de tensión social. Un buen número de las revueltas en las grandes ciudades se ha focalizado en la periferia. Por un lado, ha sido la manifestación del desacuerdo con el centro y, por otro, en el espacio interno se han desarrollado tensiones sociales en pro de algunas mejoras. Estos movimientos reivindicativos han tenido lugar gracias a una cimentación del barrio. Es decir, hay un sentimiento de colectividad que en ocasiones se desarrolló de forma clandestina y que se generó en instalaciones comunes de estas poblaciones (escuelas, parroquias, las propias fábricas, etc.). En Los príncipes valientes se narran las reuniones clandestinas en la parroquia y en el río mientras que, años después, en Paseos con mi madre, se localizan en los espacios de trabajo:

Mi padre y mis amigos, con su encierro en la iglesia, exigen la readmisión de sus compañeros despedidos y la anulación de las sanciones que les han impuesto los patronos, y protestan, por supuesto, contra la carestía de la vida, contra la subida de los precios y la congelación de los salarios, y reclaman las cuarenta horas semanales, y el derecho de la asamblea, y el derecho a huelga, y que no se modifiquen los ritmos de producción sin acuerdo previo de los trabajadores, y a través de esta jerga que escucho en las 
murmuraciones de mi madre, que ha contado que las mujeres de los obreros de otras fábricas se están encerrando con sus hijos en las iglesias. (Pérez Andújar 2007: 179-180)

Nos encontramos con un movimiento obrero más emancipado. "El obrero que toma consciencia de lo que hace y de las posibles consecuencias negativas que puede tener su conducta" y que busca "una igualdad en el trabajo y en el progreso" (Calvo 2010: 88). Hay un periodo especialmente tratado que es el de la década de los setenta, la lucha antifranquista, las reuniones clandestinas. Pero también son particularmente interesantes los años de la Transición:

La democracia la fueron conquistando estos hombres y mujeres calle por calle, árbol por árbol. La democracia es una cosa que se puede tocar, y que esa gente tuvo en sus manos durante días seguidos y noches enteras. Conseguir un colegio público en un barrio que no lo tenía; la construcción de un ambulatorio donde no llegaban los médicos; dejar una plaza sin edificar para que los niños jueguen; hacer un polideportivo para que el único deporte no sea apedrear perros; lograr que pase el autobús por donde no pasaba nada o que llegue el metro a donde no llegaba para poder ir al trabajo sin necesidad de pisar charcos, sin aguantar la lluvia y el frío de la madrugada, sin andar por los descampados que separaban el barrio de los transportes públicos, esa es la democracia que hicieron realidad estas gentes encerrándose en los locales de las asociaciones de vecinos, encadenándose a verjas, cortando el tráfico, protestando en la calle, luchando. La democracia es algo que se ve y se toca, y donde no se percibe es que no la hay. La democracia es ante todo una cosa de maniobras porque en última instancia se hace con las manos. Y todo esto que ya está, los ambulatorios, las bocas de metro, los colegios públicos..., es también lo primero que se pierde cuando desaparece la gente que lo ha traído. Quienes llegan detrás creen que eso lo pone la naturaleza, como las hierbas y los saltamontes. Pero lo pone la política, y las cosas hay que conquistarlas permanentemente. (Pérez Andújar 2011: 58-59)

Esta realidad colectiva tiene especial vigencia en los años setenta, periodo que ocupa gran parte de la segunda novela. En este periodo, los habitantes instalados en viviendas verticales carentes de sentido estético tienen conciencia de lo que les diferencia. Es el momento en que las asociaciones de vecinos, con grandes huelgas, adquieren una función social decisiva ya que reivindican la falta de equipamientos en algunos casos a través de encerronas, distribución de octavillas, metáfora de la reivindicación, y actos como secuestrar al conductor de una línea de autobús urbano para demostrar que es factible alargar el recorrido hasta el otro lado del río: 
Una tarde, en el ecuador ya de los ochenta, los vecinos van a concentrarse en San Adrián sin que ningún partido quiera convocarles y se pondrán a gritar, a abuchear [...]. La gente reclama la línea de autobús que les han quitado con el pretexto de que pronto San Adrián va a tener metro. Pero mientras tanto, de ser un sitio al que tampoco nadie ha querido ir, San Adrián habrá pasado a convertirse en un lugar del que no se puede salir. (Pérez Andújar 2011: 159-160)

Manuel Castells considera que el movimiento vecinal tuvo bastante trascendencia: "además de hacer historia, el movimiento ciudadano ha hecho otras muchas cosas a lo largo de estos años. En particular ha equipado barrios y [...] ha escuchado charlas en que la democracia y la inteligencia no podían ser palabras prohibidas" (apud Andreu 2015: 10). Estos movimientos permiten una lectura completa de la Transición. Castells remarca que las reivindicaciones vecinales se han articulado en tres ejes: la defensa de las condiciones de vida, la construcción de una identidad colectiva, social y cultural en el territorio y la defensa de una política local en las nuevas estructuras democráticas (Andreu 2015: 12). Asimismo, hace la descripción de las elecciones municipales en las cuales algunos miembros de las asociaciones de vecinos pasaron a formar parte de las listas municipales.

\section{Conclusiones}

Tras lo anteriormente expuesto, se observa que el autor proyecta lo que M. Carmen Bobes definiría como una "mirada semántica" (Bobes Naves 1985: 213) hacia un espacio. Se ha podido comprobar que el espacio y sus características constituyen un recurso importante en el proceso de elaboración de identidades urbanas y de subculturas. La disposición de los materiales aporta un testimonio de la historia social del extrarradio de Barcelona, de sus habitantes y de la problemática que les ha acompañado. Por ello, supone una obra de gran valor antropológico. Pérez Andújar construye la imagen del extrarradio a través de unas coordenadas espaciales, el topos, y unas coordenadas temporales, el cronos. Este cronotopo aporta una significación al extrarradio junto al posicionamiento crítico del autor. Este construye la identidad de un barrio no solo con la memoria personal y colectiva, sino a través de un imaginario a menudo recuperado de la cultura popular que permite configurar el espacio con unas características propias. Las similitudes entre un lado y otro de la periferia barcelonesa llevan a concluir que la población de San Adrián del Besós es una sinécdoque de un extrarradio cualquiera.

El autor concluye sus paseos y a la vez sus reflexiones con el convencimiento de que el espacio que recuerda pertenece a otra época: 
Yo también querré regresar a un país o a un lugar que no existe, pero de donde proceden las almas con las que me he criado. Mi bosque de los espíritus va a ser San Adrián, esto es lo que estoy diciendo todo el rato y para eso escribo este libro. Pero cada vez que vuelva al bosque, lo que encontraré serán edificios nuevos y mucha gente que no conozco. Las almas resulta que me las he llevado en los viajes. (Pérez Andújar 2011: 86-87)

En estos paseos, ha reivindicado un espacio y constata que es uno de los objetivos por los cuales escribe estas obras. Para ello retrata el extrarradio desde una óptica personal pero que no por ello deja de ser crítica. Pérez Andújar aporta una visión del espacio más allá de un retrato testimonial y se aleja de las imágenes estereotipadas del extrarradio, de "una época que ya no existe, pero que siempre va a pertenecerles" (Pérez Andújar 2011: 40), representadas por producciones cinematográficas en las cuales se resaltaba la delincuencia juvenil. El autor crea, a partir de su paisaje de infancia y juventud, un discurso en el cual nos viene a decir que toda ideología necesita una literatura; para él, es primordial lo que aprende de sus lecturas, y no lo que pueda aprender en un credo político.

Como bien apunta el autor, existen espacios en las grandes ciudades que se encuentran separados geográfica y socialmente de la vida del centro de la ciudad. Los habitantes que viven en estos lugares pugnan por crear una identidad. El extrarradio continúa siendo hervidero de tensiones sociales con la diferencia de que los recientes moradores proceden de una emigración internacional. No obstante, y salvo las diferencias que pueda haber de una época a otra, el desarrollo urbanístico o económico de una ciudad necesita una trastienda donde colocar aquello que no tenga ubicación y será un espacio que no responda a un orden aunque, no por ello, perderá su significación.

\section{Bibliografía}

ALBERCA, Manuel (2007): El pacto autobiográfico: de la novela autobiográfica a la autoficción. Madrid: Biblioteca Nueva.

ANDREU, Marc (2015): Barris, veïns i democràcia. El moviment ciutadà i la reconstrucció de Barcelona (1968-1986). Barcelona: L'Avenç.

AUGE, Marc (1998): Los no lugares. Espacios de anonimato. Una antropología de la sobremodernidad. Barcelona: Gedisa.

BENJAMIN, Walter (1998): Imaginación y sociedad (Iluminaciones I). Madrid: Taurus.

BOBES NAVES, M. Carmen (1985): Teoría general de la novela: semiología de "La Regenta". Madrid: Gredos.

BOU, Enric (2013): La invenció de l'espai. Ciutat i viatge. Valencia: Universitat de València. 
CALVO, Francesc (2010): El moviment obrer i la cultura popular. Barcelona: Universitat Oberta de Catalunya.

CARRERAS, Carles (2003): La Barcelona literària. Una introducció geográfica. Barcelona: Editorial Proa.

CASAS, Ana (coord.) (2012): La autoficción. Reflexiones teóricas. Madrid: Arco/Libros.

CATELLI, Nora (2007): En la era de la intimidad. Rosario: Beatriz Viterbo editora.

FERRER, Carles (2014): "Perifèries literàries". Quaderns d'estudi, núm. 28, pp. 9-31.

FUSTER, Jaume; y VÁZQUEZ MONTALBÁN, Manuel (1985): Diàlegs a Barcelona. Barcelona: Ajuntament de Barcelona / Laia.

GRAMSCI, Antonio (1967): Cultura y literatura. Madrid: Península.

HASTING, Michel (1991): Halluin la Rouge. 1919-1939. Aspects d'un communisme identitaire. Lille: Presses Universitaires de Lille.

KING, Stewart (2005): Escribir la catalanidad: lengua e identidades culturales en la narrativa contemporánea de Cataluña. Woodbridge: Támesis.

PÉREZ ANDÚJAR, Javier (2007): Los príncipes Valientes. Barcelona: Tusquets.

PÉREZ ANDÚJAR, Javier (2011): Paseos con mi madre. Barcelona: Tusquets.

PÉREZ ANDÚJAR, Javier (2014): "Entrevista a Pérez Andújar: No soy un autor social". Quimera, núm. 363, pp. 12-17.

POZUELO YVANCOS, José María (1993): Poética de la ficción. Madrid: Síntesis.

SOBEJANO, Gonzalo (1985): "La novela poemática y sus alrededores". Ínsula, vol. 40, núm. 464-465, pp. 1-26.

TÉBAR HURTADO, Javier (2011): "La clase obrera de la 'Gran Barcelona', 1951-1988. Reflexiones para el debate", en Javier Tébar Hurtado (ed.), El movimiento obrero en la gran ciudad, pp. 85-115. Barcelona: El Viejo Topo.

VALBONESI PRIETO, Fabio (2001): "El besòs crític: una aproximació a la realitat dels barris dels besòs". Revista Catalana de Sociología, núm. 14, pp.105-121. 